\title{
Synthesis and Characteristics of Hyperbranched Polybenzoxazoles via Poly(o-hydroxyamide) Precursors
}

\author{
Chi Sun Hong, Mitsutoshi JikeI, and Masa-aki KaKimoto ${ }^{\dagger}$ \\ Department of Organic and Polymeric Materials, Tokyo Institute of Technology, \\ O-okayama, Meguro-ku, Tokyo 152-8550, Japan
}

(Received February 11, 2003; Accepted August 26, 2003)

\begin{abstract}
The novel $\mathrm{AB}_{2}$ and $\mathrm{A}_{2} \mathrm{~B}$ type monomers for hyperbranched polybenzoxazoles (HBPBOs) containing one (or two) hydroxy amine and two (or one) carboxylic acid groups in the aromatic backbones were prepared starting from 5-methoxyresorcinol and 4-fluorobenzonitrile for $\mathrm{AB}_{2}$ and 3,5-dihydroxybenzoic acid and 3-fluoro-6-nitrophenol for $\mathrm{A}_{2} \mathrm{~B}$ monomer. Hyperbranched poly(o-hydroxyamide)s (HBPHAs) as precursors of HBPBOs were synthesized by self-polycondensation of the $\mathrm{AB}_{x}$ type monomers in the presence of (2,3-dihydro-2-thioxo-3-benzoxazolyl)phosphonic acid diphenyl ester (DBOP) as a condensing agent at room temperature. The terminal groups of free carboxylic acid or amine were chemically modified with 2-amino-4-tert-butylphenol or 3,5-dimethylbenzoic acid. End-capped HBPHAs had good solubility in aprotic solvents and tetrahydrofuran (THF) having the weight average molecular weight $\left(M_{\mathrm{w}}\right)$ in the range of 27000-131000. The conversion of HBPHA to HBPBO was carried out by thermal and chemical cyclization methods. HBPBOs prepared by chemical cyclization of HBPHAs in polyphosphoric acid (PPA) were soluble in aprotic solvents such as $N$-methyl-2-pyrrolidinone (NMP), $N, N$-Dimethylacetamide (DMAc), Dimethyl Formamine (DMF), and THF, whereas thermally cyclized ones were insoluble in any organic solvents. ${ }^{1} \mathrm{H}$ NMR and IR analyses indicated that the chemical cyclization proceeded quantitatively. The weight-average molecular weights $\left(M_{\mathrm{w}}\right)$ of soluble HBPBOs were found to be 23000-97000 by gel permeation chromatography (GPC) measurement with standard polystyrene calibration. Both of HBPBOs prepared by thermal and chemical cyclization methods showed excellent thermal stability having the $10 \mathrm{wt} \%$ weight loss $\left(T_{10}\right)$ in the range of $488-537^{\circ} \mathrm{C}$ under nitrogen.

KEY WORDS Polybenzoxazoles / Hyperbranched Polymer / Cyclodehydration /

Poly(o-hydroxyamide)s / One-pot Polymerization / $\mathrm{AB}_{2}$ Monomer /
\end{abstract}

The aliphatic polybenzoxazoles (PBOs) were first synthesized through the melt polycondensation of 3,3'diaminobenzidine tetrahydrochloride and sebacic acid by Brinker et al. in 1959. ${ }^{1}$ Six years later, linear aromatic polybenzoxazoles (PBOs) were first reported by Imai et $a .^{2}$ and have since been under widespread investigation. For a few decades, both of $\mathrm{AA}-\mathrm{BB}$ and $\mathrm{AB}$ type monomer systems have been studied in the synthesis of linear polybenzoxazoles having good thermal and mechanical properties. ${ }^{3-7}$ Fibers prepared from this polymer have superior tensile strength and flame retardance. PBO fibers were used in high-performance composites and comfortable protective garments. However, in spite of these attractive properties, their application has been somewhat limited since their poor processability. The processability or solubility of these polymers could be improved by the introduction of the flexible units or bulky pendant groups to the main chain. ${ }^{8-11}$

Nowadays, It is well known that dendritic macromolecules such as dendrimers or hyperbranched polymers have unusual properties compared to their linear analogues like as better solubility, lower solution viscosity and higher functionality. ${ }^{12-16}$ Although dendrimers have unique architecture, their preparation in-

${ }^{\dagger}$ To whom correspondence should be addressed. volves tedious steps such as repeating protection and deprotection reactions. On the other hand, hyperbranched polymers have some benefits of their simple preparation compared to dendrimers because they can be produced by one step polymerization of $\mathrm{AB}_{x}$ monomers. ${ }^{17-21}$ Recently, Gong et al. demonstrated the synthesis of hyperbranched poly(aryl ether oxazole)s from an $\mathrm{ABB}^{\prime}$ monomer containing a pair of phenolic groups and an aryl fluoride via nucleophilic substitution reaction. ${ }^{22}$ Baek et al. reported the synthesis of quinoxaline-benzoxazole hyperbranched polymers from an $\mathrm{AB}_{2}$ monomer in polyphosphoric acid (PPA). ${ }^{23}$ However, their solubilities of the quinoxalinebenzoxazole hyperbranched polymers were not good in common organic solvents except methansulfonic acid. We designed and prepared two types of new monomers which contain ether linkages in the main chain to give the chain flexibility. The hyperbranched polybenzoxazoles were synthesized by two step process. The two step process via precursors would result in better applicability than the one step process. For example, the poly (o-hydroxyamide) precursors are useful as thermally stable photosensitive polymers because of their appropriate dissolution rate in aqueous alkaline solution. ${ }^{24,25}$ 
Previously we reported the synthesis of hyperbranched polybenzoxazoles from an $\mathrm{AB}_{2}$ monomer as a communication. ${ }^{26}$ Herein, we describe details about the synthesis and characterization of soluble hyperbranched polybenzoxazoles having the excellent thermal stability by the one-pot condensation of novel $\mathrm{AB}_{2}$ and new $\mathrm{A}_{2} \mathrm{~B}$ type monomers via poly $(o-$ hydroxyamide) precursors.

\section{EXPERIMENTAL}

\section{Materials}

$N, N$-Dimethylacetamide (DMAc), dimethylsulfoxide (DMSO) and $N$-methyl-2-pyrrolidinone (NMP) were dried with calcium hydride and then distilled under reduced pressure. Acetic anhydride, dichloromethane and acetone were used after distillation with magnesium, calcium chloride, and calcium sulfate, respectively. Lithium chloride $(\mathrm{LiCl})$ was dried at $130^{\circ} \mathrm{C}$ in vacuo and kept under nitrogen. 3,5-Dihydroxy benzoic acid and (2,3-dihydro-2thioxo-3-benzoxazolyl)phosphonic acid diphenyl ester (DBOP) were used after recrystallization with water and $n$-hexane, respectively. Triethylamine (TEA) and 4-methylpyridine were purified by distillation in the presence of potassium hydroxide. Other solvents and reagents were used as received.

\section{Measurements}

${ }^{1} \mathrm{H}$ and ${ }^{13} \mathrm{C}$ NMR spectra were recorded on a JEOL JNM-AL $300(300 \mathrm{MHz})$ spectrometer. IR spectra were measured as a $\mathrm{KBr}$ pellet with a JASCO FT/IR-460 Plus spectrophotometer. Molecular weights were determined by gel permeation chromatography (GPC) with polystyrene calibration using a JASCO HPLC 880 PU fitted with Shodex KD $806 \mathrm{M}$ and 802.5 columns in DMF containing lithium bromide $\left(0.01 \mathrm{~mol} \mathrm{~L}^{-1}\right)$ as an eluent or SHODEX GPC-104/101 with Shodex KD $806 \mathrm{M}$ and KD 802 columns in DMF. Differential scanning calorimetry (DSC) and thermogravimetric analysis (TGA) were performed on a Seiko DSC 6200 and TG/DTA 6200, respectively. Inherent viscosity was measured at a concentration of $0.5 \mathrm{~g} \mathrm{dL}^{-1}$ with a Ostwald type viscometer in DMAc at $30^{\circ} \mathrm{C}$.

$A B_{2}$ type Monomer Preparation. Synthesis of 3,5-Bis(4-cyanophenoxy) anisole 1

In a $1000 \mathrm{~mL}$ round-bottomed three-neck flask equipped with a condenser and a gas inlet were placed 5-methoxyresorcinol (14.0 g, $0.1 \mathrm{~mol})$, 4-fluorobenzonitrile $(24.2 \mathrm{~g}, 0.2 \mathrm{~mol})$, potassium carbonate $(55.3 \mathrm{~g}, 0.4 \mathrm{~mol})$ and DMAc $(300 \mathrm{~mL})$. The reaction mixture was stirred at $150^{\circ} \mathrm{C}$ for $5 \mathrm{~h}$ and then cooled.
The resulting mixture was poured into water $(6000 \mathrm{~mL})$ and the precipitate was isolated by filtration. The crude product was washed with water and then dried at $60^{\circ} \mathrm{C}$ for one day in a vacuum oven ( $95 \%$ yield). The white crystal was obtained by recrystallization in ethanol to give 3,5-bis(4-cyanophenoxy)anisole $(30.9 \mathrm{~g})$ : $90.3 \%$ yield; mp 94-96 ${ }^{\circ} \mathrm{C} ;{ }^{1} \mathrm{H}$ NMR (DMSO- $\left.d_{6}, \mathrm{ppm}\right) \delta$ 7.81-7.86 (dd, $4 \mathrm{H}, \mathrm{Ar}-\mathrm{H}), 7.16-7.20$ (dd, $4 \mathrm{H}, \mathrm{Ar}-$ H), 6.61-6.62 (d, $2 \mathrm{H}, \mathrm{Ar}-\mathrm{H}), 6.46-6.47(\mathrm{t}, 1 \mathrm{H}, \mathrm{Ar}-$ $\mathrm{H}), 3.74\left(\mathrm{~s}, 3 \mathrm{H}\right.$, methoxy); IR (KBr) $2230 \mathrm{~cm}^{-1}$ (cyano group).

\section{Synthesis of 3,5-Bis(4-cyanophenoxy)-2-nitroanisole 2}

To a $1000 \mathrm{~mL}$ round-bottomed three-neck flask equipped with a gas inlet were added 3,5-bis(4cyanophenoxy)anisole $1(27.4 \mathrm{~g}, 80 \mathrm{mmol})$ and $300 \mathrm{~mL}$ of acetic anhydride. Cupric nitrate trihydrate $(24.2 \mathrm{~g}$, $100 \mathrm{mmol}$ ) was added slowly into the same flask at room temperature and stirred for $5 \mathrm{~h}$ after the addition. The reaction mixture was poured into cold water and the crude product was isolated by filtration. The crude product was washed with water twice and then dried at room temperature for two days in a vacuum oven. The yellow product was recrystallized from ethanol to give 3,5-bis(4-cyanophenoxy)-2-nitroanisole (13.6 g): $44.0 \%$ yield; $\mathrm{mp} 53-55^{\circ} \mathrm{C} ;{ }^{1} \mathrm{H}$ NMR (DMSO- $d_{6}, \mathrm{ppm}$ ) $\delta$ 7.83-7.87 (m, 4 H, Ar-H), 7.24-7.32 (m, 4 H, ArH), 7.03-7.04 (d, $1 \mathrm{H}, \mathrm{Ar}-\mathrm{H}), 6.63-6.64(\mathrm{~d}, 1 \mathrm{H}, \mathrm{Ar}-$ $\mathrm{H}), 3.91$ (s, $3 \mathrm{H}$, methoxy); IR (KBr) $1536 \mathrm{~cm}^{-1}$ (nitro group), $1341 \mathrm{~cm}^{-1}$ (nitro group).

\section{Synthesis of 3,5-Bis(4-cyanophenoxy)-2-nitrophenol 3}

To a $500 \mathrm{~mL}$ round-bottomed three-neck flask equipped with a gas inlet were added 3,5-bis(4cyanophenoxy)-2-nitro anisole 2 (11.62 g, $30 \mathrm{mmol})$ and $150 \mathrm{~mL}$ of anhydrous dichloromethane under nitrogen. Boron tribromide $(11.3 \mathrm{~mL}, 120 \mathrm{mmol})$ was added slowly via syringe to the flask cooled by dry-ice at $-50^{\circ} \mathrm{C}$. After the removal of the dry-ice bath, the reaction mixture was stirred for 5-6h and then for $20 \mathrm{~h}$ at room temperature. The resulting mixture was poured into $1000 \mathrm{~mL}$ of cold water and then extracted with diethyl ether. The extract was washed with cold water and then dried with anhydrous magnesium sulfate. Yellow crude product was obtained after evaporation and dried at $60^{\circ} \mathrm{C}$ for one day in a vacuum oven $(99.0 \%$ yield). The yellow crude product was purified by column chromatography in ethyl acetate and hexane as eluents and recrystallized from a mixture of ethanol and water to give a light yellow crystal $(8.9 \mathrm{~g}): 79.3 \%$ yield; mp $150-151{ }^{\circ} \mathrm{C} ;{ }^{1} \mathrm{H}$ NMR (DMSO- $d_{6}$, ppm) $\delta 11.72$ (s, $1 \mathrm{H} \mathrm{Ar}-\mathrm{OH}), 7.84-7.90$ (m, $4 \mathrm{H}, \mathrm{Ar}-\mathrm{H}), 7.24-7.34$ (m, $4 \mathrm{H}, \mathrm{Ar}-\mathrm{H}), 6.52-6.53$ (d, $1 \mathrm{H}, \mathrm{Ar}-\mathrm{H}), 6.50-6.51$ 
(d, $1 \mathrm{H}, \mathrm{Ar}-\mathrm{H})$; IR (KBr) $3500 \mathrm{~cm}^{-1}$ (hydroxy group), $1536 \mathrm{~cm}^{-1}$ (nitro group), $1341 \mathrm{~cm}^{-1}$ (nitro group).

\section{Synthesis of 3,5-Bis(4-carboxylphenoxy)-2-nitrophe- nol 4}

To a $200 \mathrm{~mL}$ round-bottomed flask equipped with a condenser and a gas inlet were added 3,5-bis(4cyanophenoxy)-2-nitrophenol 3 (7.47 g, $20 \mathrm{mmol})$ and $75 \mathrm{~mL}$ of phosphoric acid (85\%). The reaction mixture was stirred for $4 \mathrm{~h}$ under reflux and then cooled to room temperature. The resulting mixture was poured into cold water and then stirred at room temperature for $6 \mathrm{~h}$ after adjusting the $\mathrm{pH}$ value to $11 \mathrm{in}$ order to remove insoluble particles through filtration. After neutralization with hydrochloric acid to $\mathrm{pH} 3-4$, the precipitate was isolated by filtration and washed with dilute hydrochloric acid and water. The crude product was dried at $80^{\circ} \mathrm{C}$ for one day in a vacuum oven $(94.0 \%$ yield). The yellow crude product was purified by column chromatography in tetrahydrofuran and hexane as eluents to give a light yellow powder $(7.1 \mathrm{~g}): 86.5 \%$ yield; $\mathrm{mp}$ 267-269 ${ }^{\circ} \mathrm{C} ;{ }^{1} \mathrm{H}$ NMR (DMSO- $\left.d_{6}, \mathrm{ppm}\right) \delta 12.93$ (s, $2 \mathrm{H}$ Ar-COOH), 11.59 (s, $1 \mathrm{H} \mathrm{Ar}-\mathrm{OH}), 7.93-7.98$ (m, $4 \mathrm{H}$, Ar-H), 7.15-7.22 (m, 4 H, Ar-H), 6.45-6.46 (d, $1 \mathrm{H}$, Ar-H), 6.34-6.35 (d, $1 \mathrm{H}, \mathrm{Ar}-\mathrm{H})$; IR (KBr) $1692 \mathrm{~cm}^{-1}$ (carboxylic group).

Synthesis of 3,5-Bis(4-carboxylphenoxy)-2-aminophenol Hydrochloride ( $A B_{2}$ monomer, 5)

To a $100 \mathrm{~mL}$ of high-pressure reactor, 3,5-bis(4carboxylphenoxy)-2-nitrophenol 4 (6.17 g, $15 \mathrm{mmol})$, $10 \%$ palladium-charcoal catalyst $(0.62 \mathrm{~g})$ and $70 \mathrm{~mL}$ of a mixture of methanol and tetrahydrofuran (50:50 $(\mathrm{v} / \mathrm{v}))$ were charged. The reaction mixture was stirred under hydrogen of $14 \mathrm{~kg}_{\mathrm{f}} \mathrm{cm}^{-2}$ at room temperature for $48 \mathrm{~h}$. The resulting mixture was filtered with celite to remove the catalyst. The dark purple filtrate was concentrated by evaporation and then hydrochloride was added to the concentrated solution. The mixture was stirred for $6 \mathrm{~h}$ at room temperature and then poured into diethyl ether. The precipitate was isolated by filtration. The light brown powder was dried at $40^{\circ} \mathrm{C}$ for $2 \mathrm{~d}$ in a vacuum oven to give 3,5bis(4-carboxylphenoxy)-2-aminophenol hydrochloride (5.8 g): $92.5 \%$ yield; ${ }^{1} \mathrm{H}$ NMR (DMSO- $\left.d_{6}, \mathrm{ppm}\right) \delta$ 11.16 (brs, $2 \mathrm{H}, \mathrm{Ar}-\mathrm{COOH}), 7.91-7.97$ (m, 4 H, ArH), 7.05-7.14 (m, 4 H, Ar-H), 6.51-6.52 (d, $1 \mathrm{H}, \mathrm{Ar}-$ $\mathrm{H}), 6.22-6.23(\mathrm{~d}, 1 \mathrm{H}, \mathrm{Ar}-\mathrm{H}) ;{ }^{13} \mathrm{C}$ NMR (DMSO- $d_{6}$, ppm) $\delta 166.6,160.2,159.5,153.3,152.2,149.0,131.7$, $131.6,126.3,125.8,118.1,117.7,102.9,101.5$; IR (KBr) $3413 \mathrm{~cm}^{-1}, 3072 \mathrm{~cm}^{-1}, 1691 \mathrm{~cm}^{-1}$ (carboxylic group). Anal. Calcd for $\mathrm{C}_{20} \mathrm{H}_{16} \mathrm{ClNO}_{7}: \mathrm{C}, 57.50 ; \mathrm{H}$,
3.86; N, 3.35. Found: C, 57.32; H, 4.01; N, 3.14.

$A_{2} B$ type Monomer Preparation. Synthesis of 2-Benzyloxy-4-fluoronitro Benzene 6

To a $500 \mathrm{~mL}$ round-bottomed flask equipped with a condenser and a gas inlet were added 3-fluoro-6-nitrophenol $(15.71 \mathrm{~g}, 0.1 \mathrm{~mol})$, benzyl bromide $(17.10 \mathrm{~g}$, $0.1 \mathrm{~mol})$, potassium carbonate $(27.64 \mathrm{~g}, 0.2 \mathrm{~mol})$ and $190 \mathrm{~mL}$ of acetone under nitrogen. The reaction mixture was refluxed for $7 \mathrm{~h}$ and then cooled to room temperature. The resulting mixture was poured into water $(1800 \mathrm{~mL})$. The crude product was isolated by filtration and recrystallized from ethanol. Bright yellow needlelike crystal was obtained after dried at room temperature for overnight: $80.9 \%$ yield; $\mathrm{mp} 53-55^{\circ} \mathrm{C}$; ${ }^{1} \mathrm{HNMR}$ (DMSO- $\left.d_{6}, \mathrm{ppm}\right) \delta 8.00-8.05(\mathrm{~m}, 1 \mathrm{H}, \mathrm{Ar}-\mathrm{H}), 7.31-$ $7.47(\mathrm{~m}, 6 \mathrm{H}, \mathrm{Ar}-\mathrm{H}), 6.94-7.01(\mathrm{~m}, 1 \mathrm{H}, \mathrm{Ar}-\mathrm{H}), 5.31$ (s, $2 \mathrm{H},-\mathrm{CH}_{2}$ ); IR (KBr) $1522 \mathrm{~cm}^{-1}, 1351 \mathrm{~cm}^{-1}$. Anal. Calcd for $\mathrm{C}_{13} \mathrm{H}_{10} \mathrm{FNO}_{3}$ : C, 63.16; H, 4.08; N, 5.67. Found: C, 63.13; H, 4.12; N, 5.60.

Synthesis of 3,5-Bis(3-benzyloxy-4-nitrophenoxy)benzoic Acid 7

In a three-neck flask equipped with a Dean-Stark trap, a condenser and a nitrogen inlet were put 3,5dihydroxybenzoic acid $(3.08 \mathrm{~g}, 20 \mathrm{mmol})$, potassium carbonate $(16.58 \mathrm{~g}, 120 \mathrm{mmol})$, toluene $(30 \mathrm{~mL})$ and $60 \mathrm{~mL}$ of DMSO. The reaction mixture was heated with stirring at $155^{\circ} \mathrm{C}$ for $3 \mathrm{~h}$ under nitrogen, and during this period the water formed was collected in the Dean-Stark trap. After cooling the flask to room temperature, 2-benzyloxy-4-fluoronitrobenzene $6(9.89 \mathrm{~g}$, $40 \mathrm{mmol}$ ) was added into the flask. The reaction mixture was heated to $100^{\circ} \mathrm{C}$ for $20 \mathrm{~h}$ and then allowed to cool to room temperature. The reaction mixture was poured into cold water $(1500 \mathrm{~mL})$ and then neutralized with dilute hydrochloride. The white powdery product was isolated by filtration and purified by column chromatography in a mixture of tetrahydrofuran and hexane $(50: 50(\mathrm{v} / \mathrm{v}))$ as an eluent to give a light yellow powder. The light yellow crystal was obtained after recrystallization in a mixture of ethyl acetate and hexane (40:60 (v/v)): $52.3 \%$ yield; mp $161-163{ }^{\circ} \mathrm{C} ;{ }^{1} \mathrm{HNMR}$ (DMSO- $d_{6}$, ppm) $\delta 7.98-8.01(\mathrm{~d}, 2 \mathrm{H}, \mathrm{Ar}-\mathrm{H}), 7.26-$ 7.43 (m, 12 H, Ar-H), 7.17-7.18 (d, 2 H, Ar-H), 6.72$6.76(\mathrm{dd}, 2 \mathrm{H}, \mathrm{Ar}-\mathrm{H}), 5.28\left(\mathrm{~s}, 4 \mathrm{H},-\mathrm{CH}_{2}\right)$; IR $(\mathrm{KBr})$ $1700 \mathrm{~cm}^{-1}, 1516 \mathrm{~cm}^{-1}, 1348 \mathrm{~cm}^{-1}$. Anal. Calcd for $\mathrm{C}_{33} \mathrm{H}_{24} \mathrm{~N}_{2} \mathrm{O}_{10}$ : C, 65.13; H, 3.98; N, 4.60. Found: C, $65.05 ; \mathrm{H}, 4.03 ; \mathrm{N}, 4.47$. 
Synthesis of 3,5-Bis(4-amino-3-hydroxyphenoxy)benzoic Acid Dihydrochloride $\left(A_{2} B\right.$ monomer, 8$)$

To a $100 \mathrm{~mL}$ of high-pressure reactor, 3,5-bis(3benzyloxy-4-nitro-phenoxy)-benzoic acid $(6.09 \mathrm{~g}$, $10 \mathrm{mmol}), 10 \%$ palladium-charcoal catalyst $(0.61 \mathrm{~g})$ and $70 \mathrm{~mL}$ of a mixture of methanol and tetrahydrofuran $(50: 50(\mathrm{v} / \mathrm{v}))$ were charged. The following procedure was similar to that of preparation of $\mathbf{5}$. The light purple powder was dried at $40^{\circ} \mathrm{C}$ for $2 \mathrm{~d}$ in the vacuum oven to give 3,5-bis(4-amino3-hydroxyphenoxy)-benzoic acid dihydrochloride (4.21 g): 95.5\% yield; ${ }^{1} \mathrm{HNMR}$ (DMSO- $d_{6}, \mathrm{ppm}$ ) $\delta 11.13(\mathrm{~s}, 1 \mathrm{H}, \mathrm{Ar}-\mathrm{COOH}), 9.91(\mathrm{br}, 2 \mathrm{H}, \mathrm{Ar}-\mathrm{OH})$, 7.37-7.40 (d, $2 \mathrm{H}, \mathrm{Ar}-\mathrm{H}), 7.18-7.19$ (m, 2 H, Ar-H), 7.01-7.02 (t, $1 \mathrm{H}, \mathrm{Ar}-\mathrm{H}), 6.78-6.79(\mathrm{~d}, 2 \mathrm{H}, \mathrm{Ar}-\mathrm{H})$, 6.60-6.64 (m, $2 \mathrm{H}, \mathrm{Ar}-\mathrm{H}) ;{ }^{13} \mathrm{C}$ NMR (DMSO- $d_{6}, \mathrm{ppm}$ ) $\delta$ 165.96, 157.97, 155.70, 152.21, 134.14, 125.27, $115.68,113.52,113.41,109.87,106.88$; IR (KBr) $3372 \mathrm{~cm}^{-1}, 2955 \mathrm{~cm}^{-1}, 1701 \mathrm{~cm}^{-1}$ (carboxylic group). Anal. Calcd for $\mathrm{C}_{19} \mathrm{H}_{18} \mathrm{Cl}_{2} \mathrm{~N}_{2} \mathrm{O}_{6}: \mathrm{C}, 51.72 ; \mathrm{H}, 4.11 ; \mathrm{N}$, 6.35. Found: C, 51.58; H, 4.30; N, 6.21.

\section{Preparation of Polymer P4}

Polymer P4 was prepared by polycondensation of $\mathrm{A}_{2} \mathrm{~B}$ type monomer $(\mathbf{8}, 0.41 \mathrm{~g}, 1.0 \mathrm{mmol})$ with DBOP $(0.38 \mathrm{~g}, 1.0 \mathrm{mmol})$, dried $\mathrm{LiCl}(0.09 \mathrm{~g}, 2.0 \mathrm{mmol})$ and $4-$ methyl pyridine $(0.29 \mathrm{~mL}, 3.0 \mathrm{mmol})$ in $3 \mathrm{~mL}$ of NMP under nitrogen. The reaction mixture was stirred at room temperature for $5 \mathrm{~h}$. The end-capping solution composed of 3,5-dimethylbenzoic acid $(2.0 \mathrm{mmol})$, $\operatorname{DBOP}(0.77 \mathrm{~g}, 2.0 \mathrm{mmol})$, 4-methylpyridine $(0.20 \mathrm{~mL}$, $2.0 \mathrm{mmol}$ ) and $4 \mathrm{~mL}$ of NMP was added slowly to the reaction mixture and stirred for additional $4 \mathrm{~h}$. The reaction mixture was poured into $600 \mathrm{~mL}$ of methanol containing $0.1 \mathrm{wt} \%$ lithium chloride. The precipitated polymer was isolated by filtration, and dissolved in Dimethyl Formamide(DMF). After reprecipitation in methanol, the product was filtered, and dried at room temperature for two days in a vacuum oven: $67.4 \%$ yield; ${ }^{1} \mathrm{H}$ NMR (DMSO- $d_{6}$, ppm) $\delta 9.38-9.61(\mathrm{~d}, 2 \mathrm{H})$, 7.46-7.64 (m, $4 \mathrm{H}, \mathrm{Ar}-\mathrm{H}), 7.33$ (s, $2 \mathrm{H}, \mathrm{Ar}-\mathrm{H}), 7.17$ (s, $1 \mathrm{H}, \mathrm{Ar}-\mathrm{H}), 6.82(\mathrm{~s}, 1 \mathrm{H}, \mathrm{Ar}-\mathrm{H}), 6.55-6.62(\mathrm{~m}, 4 \mathrm{H}$, Ar-H), 2.30 (s, 6 H, methyl); ${ }^{13} \mathrm{C}$ NMR (DMSO- $d_{6}$, ppm) $\delta 165.55,163.91,158.25,158.03,154.05,153.40$, $151.91,150.98,137.65,137.49,134.32,132.94$, $127.30,127.00,125.65,125.37,125.24,122.36$, $121.53,112.16,111.50,109.52,109.27,109.24$, 106.83, 106.60, 20.85; IR (KBr) $1655 \mathrm{~cm}^{-1}$ (amide).

\section{Thermal Cyclodehydration}

Polymer P5 was prepared as follows. Poly $(o-$ hydroxyamide) (P4) (0.5 g) was dissolved in $2.0 \mathrm{~mL}$ of NMP for overnight. The solution was cast on a glass plate and cured in a vacuum oven for $1 \mathrm{~h}$ at room temperature, $100^{\circ} \mathrm{C}, 200^{\circ} \mathrm{C}$, and $300^{\circ} \mathrm{C}$, respectively and finally cooled to room temperature slowly: IR $(\mathrm{KBr})$ $1623 \mathrm{~cm}^{-1} \quad(-\mathrm{C}=\mathrm{N}), 1593 \mathrm{~cm}^{-1} \quad(\mathrm{C}=\mathrm{C}), 1474 \mathrm{~cm}^{-1}$, $1079 \mathrm{~cm}^{-1}(\mathrm{C}-\mathrm{O}-\mathrm{C})$.

\section{Chemical Cyclodehydration}

Polymer P6 was prepared as follows. To a $100 \mathrm{~mL}$ round-bottomed flask equipped with a gas inlet were added $0.5 \mathrm{~g}$ of poly( $o$-hydroxyamide) (P4) and $20 \mathrm{~g}$ of polyphosphoric acid (PPA). The reaction mixture was heated slowly to $160^{\circ} \mathrm{C}$ and stirred for $24 \mathrm{~h}$. The resulting mixture was poured into cold water $(400 \mathrm{~mL})$ and isolated by filtration. The precipitate was washed with diluted sodium bicarbonate and then dried at $30^{\circ} \mathrm{C}$ for $1 \mathrm{~d}$ in a vacuum oven: $85 \%$ yield; ${ }^{1} \mathrm{H}$ NMR (DMSO- $\left.d_{6}, \mathrm{ppm}\right) \delta 7.75$ (br, $4 \mathrm{H}, \mathrm{Ar}-\mathrm{H}$ ), $7.16(\mathrm{br}, 3 \mathrm{H}, \mathrm{Ar}-\mathrm{H}), 6.60(\mathrm{br}, 5 \mathrm{H}, \mathrm{Ar}-\mathrm{H}), 2.29$ (s, $6 \mathrm{H}$, methyl); IR $(\mathrm{KBr}) 1622 \mathrm{~cm}^{-1}(-\mathrm{C}=\mathrm{N}), 1593 \mathrm{~cm}^{-1}$ $(\mathrm{C}=\mathrm{C}), 1475 \mathrm{~cm}^{-1}, 1079 \mathrm{~cm}^{-1}(\mathrm{C}-\mathrm{O}-\mathrm{C})$.

\section{RESULTS AND DISCUSSION}

\section{Monomer Synthesis}

We prepared two types of new monomers for HBPBO (Scheme 1). The monomers were designed to enhance the solubility of corresponding polymers by introduction of flexible ether units in the backbone. $\mathrm{An} \mathrm{AB}_{2}$ type monomer, 3,5-bis(4-carboxylphenoxy)2-aminophenol hydrochloride 5, was prepared starting from 5-methoxyresorcinol and 4-fluorobenzonitrile as described in previous report. ${ }^{26}$

On the other hand, an $\mathrm{A}_{2} \mathrm{~B}$ type monomer, 3,5bis(4-amino-3-hydroxy-phenoxy) benzoic acid dihydrochloride 8, was prepared starting from 3-fluoro-6nitrophenol and 3,5-dihydroxybenzoic acid as shown in Scheme 2. The hydroxy group of the 3-fluoro6-nitrophenol was protected with benzyl bromide in the presence of potassium carbonate to afford 2benzyloxy-4-fluoronitrobenzene $\mathbf{6}$, which was subsequently reacted with 3,5-dihydroxybenzoic acid in $\mathrm{N}, \mathrm{N}$-dimethylacetamide (DMAc), yielding 3,5-bis(3benzyloxy-4-nitrophenoxy)benzoic acid 7. Finally

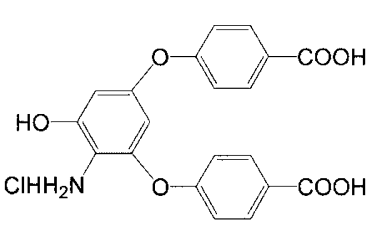

$\mathrm{AB}_{2}$ type monomer

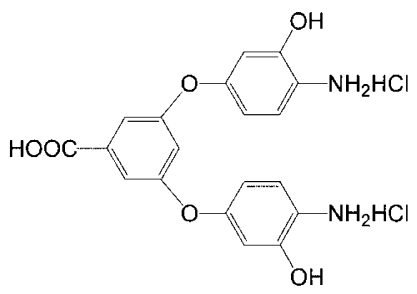

$\mathrm{A}_{2} \mathrm{~B}$ type monomer
Scheme 1. Two types of monomers. 
monomer $\mathbf{8}$ was prepared by reduction of compound 7 in the presence of $10 \%$ palladium-charcoal catalyst and following acidification by hydrochloric acid. Total yield of the monomer 8 from 3-fluoro-6-nitrophenol was $40 \%$. The structure of monomer 8 was characterized by ${ }^{1} \mathrm{H},{ }^{13} \mathrm{C} N M R$, IR, and elementary analysis. The IR spectra of monomer 8 showed characteristic $\mathrm{N}-\mathrm{H}$ $\left(3372 \mathrm{~cm}^{-1}\right), \mathrm{O}-\mathrm{H}\left(2955 \mathrm{~cm}^{-1}\right)$ and $\mathrm{C}=\mathrm{O}\left(1701 \mathrm{~cm}^{-1}\right)$ peaks. All of the peaks in the ${ }^{1} \mathrm{H}$ NMR spectrum were well assigned to estimated structure (Figure 1).

\section{Synthesis of End-capped Poly(o-hydroxyamide)s}

Ueda et al. demonstrated the effect of DBOP as a condensing agent for the chemoselective polycondensation of polyamides. ${ }^{27,28}$ They revealed that polyamides could be prepared readily by the chemoselective polyamidation of dicarboxylic acids with

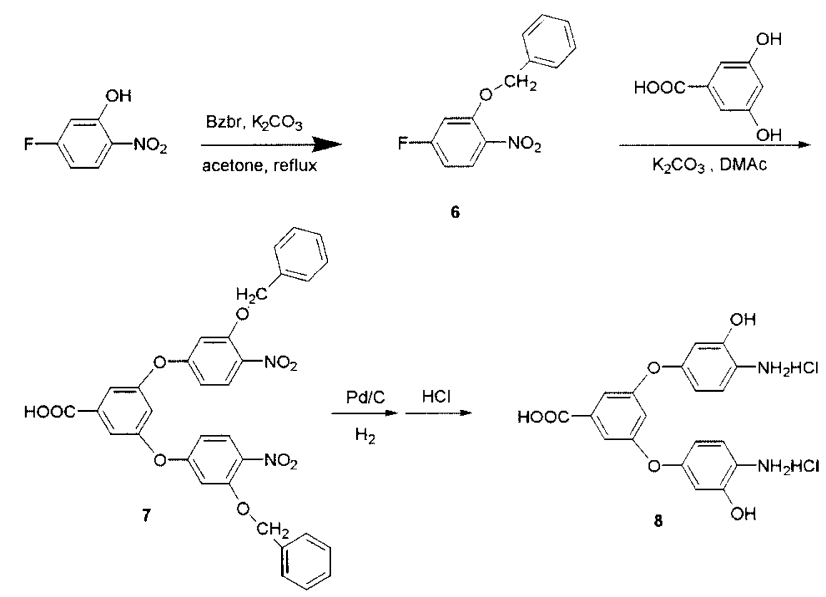

Scheme 2. Synthesis of $A_{2} B$ type monomer 8 . diamines containing various functional groups via DBOP at room temperature. We previously reported the synthesis of $\mathrm{HBPBO}$ from an $\mathrm{AB}_{2}$ monomer (Scheme 3). The free carboxylic end-groups were chemically modified with 2-amino-4-tert-butyl phenol as an end-capping agent without isolation of $\operatorname{poly}(o-$ hydroxyamide), since isolated HBPHA was insoluble in aprotic solvents. The conversion of the end-capping reaction calculated from the integration ratios between the characteristic tert-butyl peaks at $1.21 \mathrm{ppm}$ and aromatics at $6.45 \mathrm{ppm}$ by ${ }^{1} \mathrm{HNMR}$ analysis was $85 \%$ (spectrum P1 in Figure 2). The conversion was not influenced by the quantity of end-capping agent in the range of 5-10 times excess. The degree of branching (DB) of hyperbranched polymers was defined as the ratio of the sum of dendritic and terminal units versus total units (dendritic, terminal and linear units). Unfortunately, the DB values of $\mathbf{P 1}$ could not be calculated by ${ }^{1} \mathrm{H}$ and ${ }^{13} \mathrm{C}$ NMR analyses since the each peaks of dendritic, linear, and terminal units were not distinguishable.

Polymer P4 was prepared by polycondensation of the $\mathrm{A}_{2} \mathrm{~B}$ monomer 8 in the presence of DBOP and 4-methylpyridine in NMP as shown in Scheme 3.

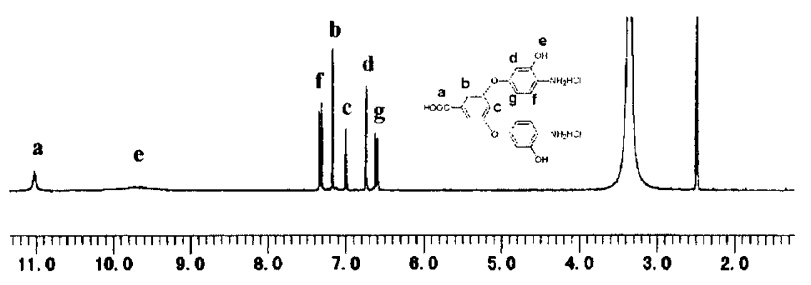

Figure 1. ${ }^{1} \mathrm{H} \mathrm{NMR}$ spectrum of $\mathrm{A}_{2} \mathrm{~B}$ type monomer.

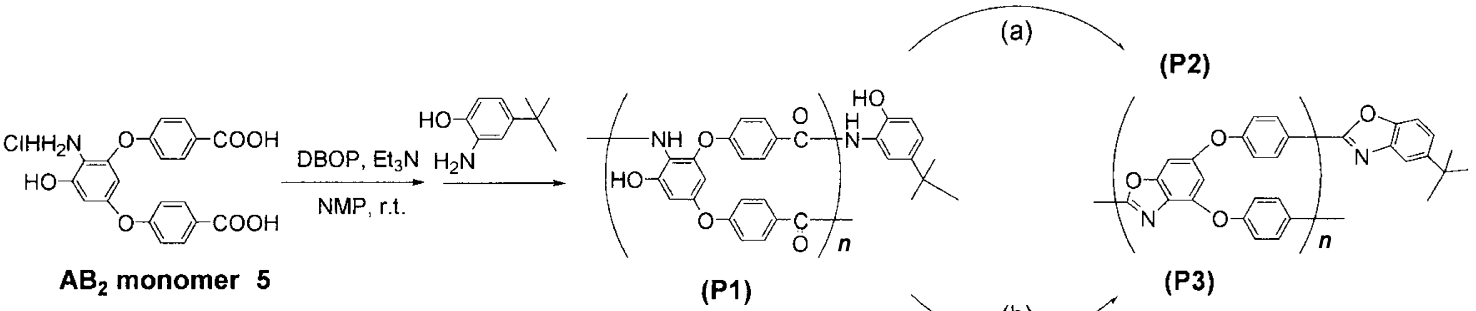

(b)

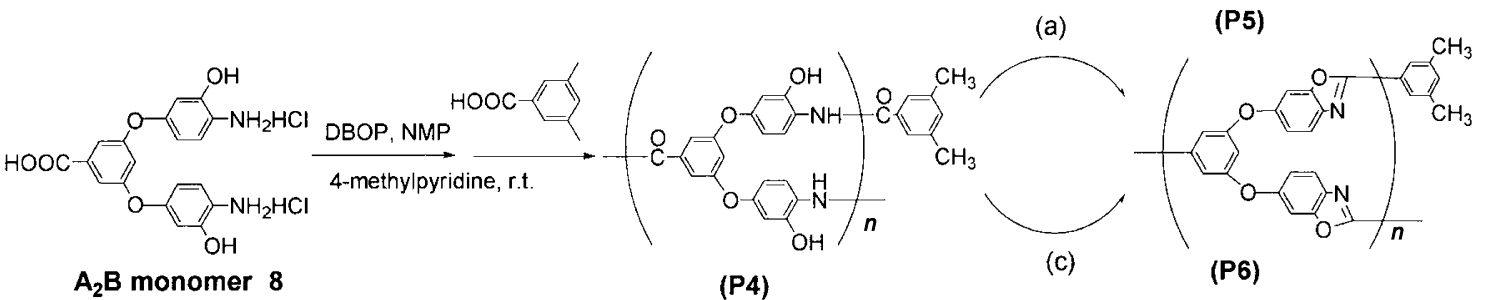

Scheme 3. Synthesis of polymers from the two types of monomers. (a): Thermal cyclization at room temperature, $100^{\circ} \mathrm{C}, 200^{\circ} \mathrm{C}$, and $300^{\circ} \mathrm{C}$ for $1 \mathrm{~h}$ in vacuo; (b): Chemical cyclization in polyphosphoric acid at $130^{\circ} \mathrm{C}$ for $36 \mathrm{~h}$; (c): Chemical cyclization in polyphosphoric acid at $160^{\circ} \mathrm{C}$ for $24 \mathrm{~h}$. 


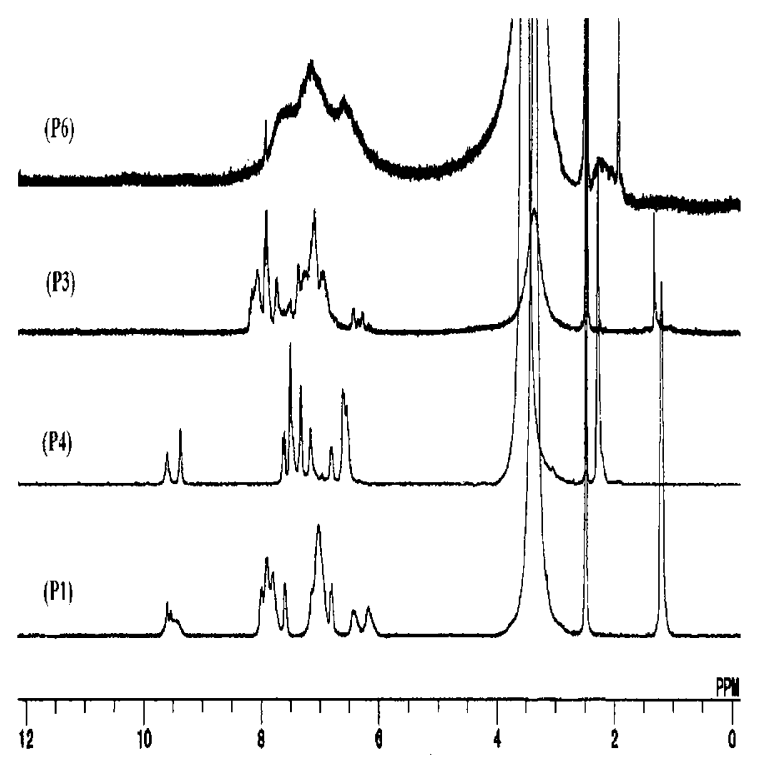

Figure 2. ${ }^{1} \mathrm{H}$ NMR spectra of HBPHA precursors (P1, P4), and chemically cyclized HBPBOs (P3, P6).

The free amino end groups were chemically modified with 3,5-dimethylbenzoic acid. The end-capping solution was prepared by mixing 3,5-dimethylbenzoic acid, DBOP and 4-methyl pyridine in NMP to form the active amide, which is the profer intermediate for chermoselective amidation. ${ }^{27,28}$ An excess usage of endcapping solution raised the formation of not only amidation, but undesirable esterification. The desirable poly(o-hydroxyamide) could be prepared by using an equimolar amount of the end-capping agents. The conversion of the end-capping reaction was $95 \%$, which was calculated from the comparison of methyl peaks at $2.3 \mathrm{ppm}$ and aromatics at $6.6 \mathrm{ppm}$ by ${ }^{1} \mathrm{H}$ NMR analysis (spectrum $\mathbf{P 4}$ in Figure 2). The DB values of P4 could not be calculated by ${ }^{1} \mathrm{H}$ and ${ }^{13} \mathrm{C}$ NMR analyses because of the same reasons as P1. Polymer P4 showed good solubility in common organic solvents, similar to P1 (Table I). The effect of the monomer concentration on $\eta_{\text {inh }}$ was investigated as shown in Figure 3. $\eta_{\text {inh }}$ increased with increasing the concentration of monomer up to $13.5 \mathrm{~g} \mathrm{dL}^{-1}$, but the gelation was occurred when the concentration of monomer was $27 \mathrm{~g} \mathrm{dL}^{-1}$.

\section{Conversion of HBPHA to HBPBO by Thermal and Chemical Cyclodehydration}

The conversion of HBPHA to HBPBO was carried out by two ways, thermal and chemical cyclodehydration. We have monitored the thermal conversion of HBPHA to HBPBO with temperature variation by IR as shown in Figure 4. The characteristic amide peaks of P1 were observed at $1654 \mathrm{~cm}^{-1}$. The peak intensity was decreased gradually with temperature and disappeared completely above $300^{\circ} \mathrm{C}$. Whereas, two new characteristic peaks for benzoxazole at $1618 \mathrm{~cm}^{-1}$ and
Table I. Solubility of Hyperbranched Poly(o-hydroxyamide)s and Polybenzoxazoles

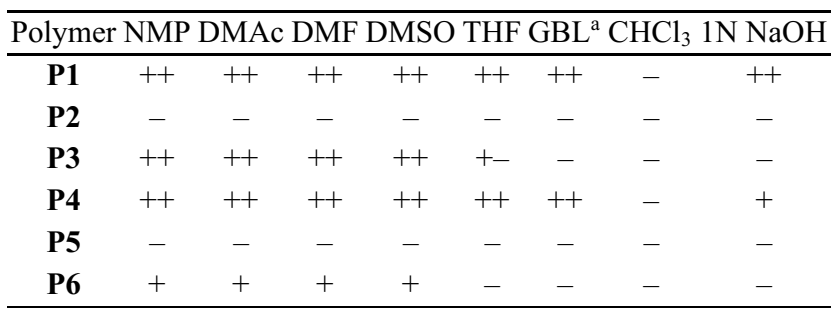

${ }^{\text {a }} \gamma$-butyrolactone; ++ , soluble at room temperature; + , soluble on heating; +-, partially soluble; - , insoluble.

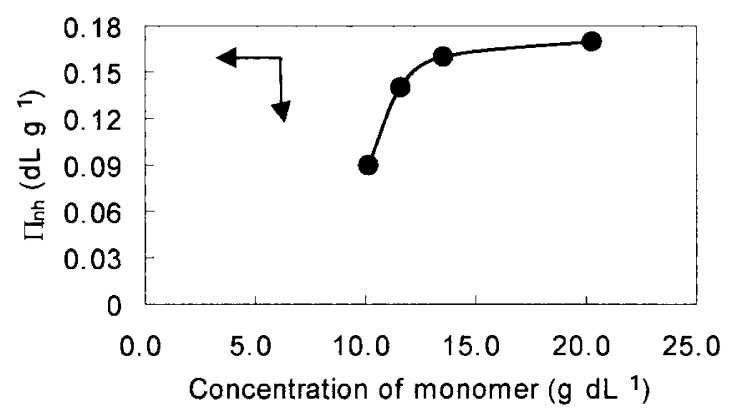

Figure 3. Inherent viscosity of polymer $\mathbf{P 4}$ with concentration of monomer $\mathbf{8}$.

$1477 \mathrm{~cm}^{-1}$ were clearly observed above $250^{\circ} \mathrm{C}$. The spectral change indicated that the thermal conversion of $\mathbf{P 1}$ to $\mathbf{P 2}$ was completed above $300^{\circ} \mathrm{C}$ for $1 \mathrm{~h}$ in vacuo. The small peak at $1700 \mathrm{~cm}^{-1}$ was observed in Figure 4a, which results from the unreacted free carboxylic end-groups. Polymer P4 was also showed the similar results of $\mathbf{P 1}$. P5 prepared from $\mathbf{P 4}$ by thermal treatment at $300^{\circ} \mathrm{C}$ for $1 \mathrm{~h}$ under vacuum was insoluble in organic solvents used in this work, similar to $\mathbf{P 2}$. This insolubility of thermally cyclized HBPBOs was anticipated to be caused by inter- or intra-molecular cross-linking during the thermal cyclization.

The DSC thermograms in Figure 5 showed that the maximum temperature $\left(T_{\max }\right)$ for thermal cyclodehydration of $\mathbf{P 4}\left(288^{\circ} \mathrm{C}\right)$ was slightly higher than that of P1 $\left(274^{\circ} \mathrm{C}\right)$. The TGA thermograms also showed that the weight loss caused by elimination of water in the cyclization step of $\mathbf{P 4}$ took place in the range of 255$318^{\circ} \mathrm{C}$, whereas that of $\mathbf{P 1}$ was observed around 241$312^{\circ} \mathrm{C}$ (thermogram (a) in Figure 6). DSC and TGA results explain that $\mathbf{P 4}$ requires a slightly higher cyclizing temperature to convert $\mathrm{PBO}$ compared to $\mathbf{P 1}$.

Polymer P6 was prepared by chemical cyclization of P4 in polyphosphoric acid (PPA) at $160^{\circ} \mathrm{C}$ for $24 \mathrm{~h}$, which is slightly severe condition compared to those of P3. Under the same condition of $\mathbf{P 1}\left(130^{\circ} \mathrm{C}, 36 \mathrm{~h}\right)$, the precursor $\mathbf{P} 4$ was not completely converted to HBPBO. The difference between the two chemical cyclization conditions was probably due to the gap of cyclized temperature between $\mathbf{P 1}$ and $\mathbf{P 4}$ as shown in Figures 5 

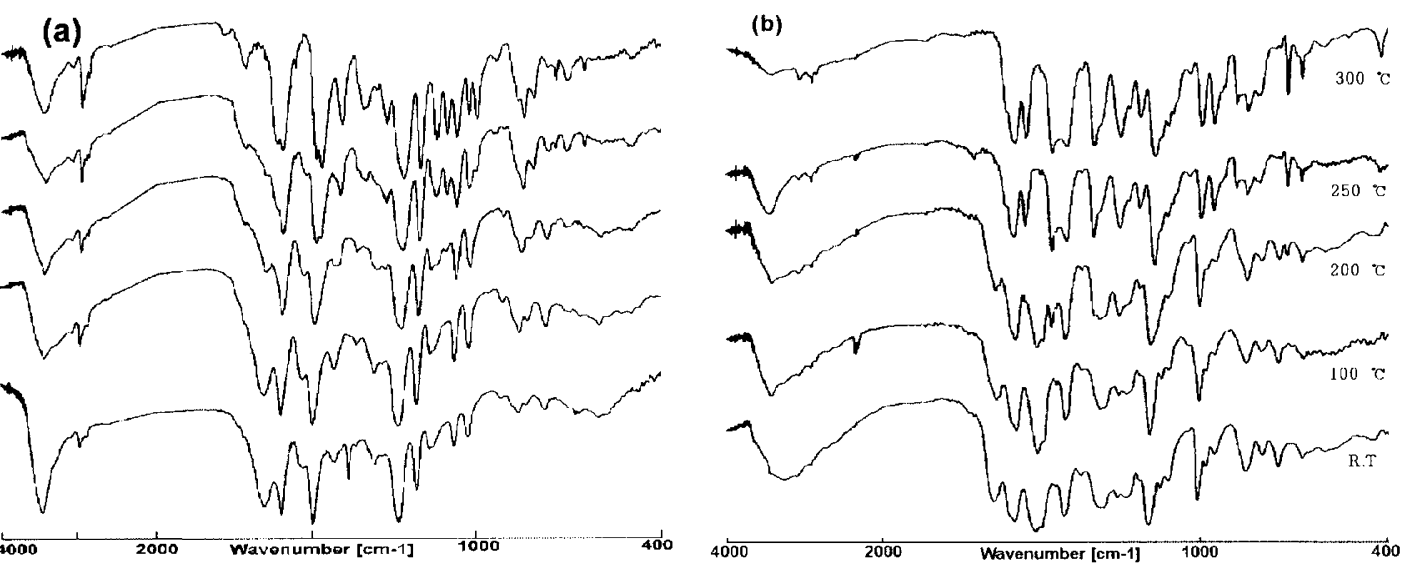

Figure 4. IR spectra of HBPHAs with heat treatment at r.t., $100^{\circ} \mathrm{C}, 200^{\circ} \mathrm{C}, 250{ }^{\circ} \mathrm{C}$, and $300^{\circ} \mathrm{C}$ for $1 \mathrm{~h}$ in vacuo. (a) $\mathbf{P 1}$ and (b) $\mathbf{P 4}$.

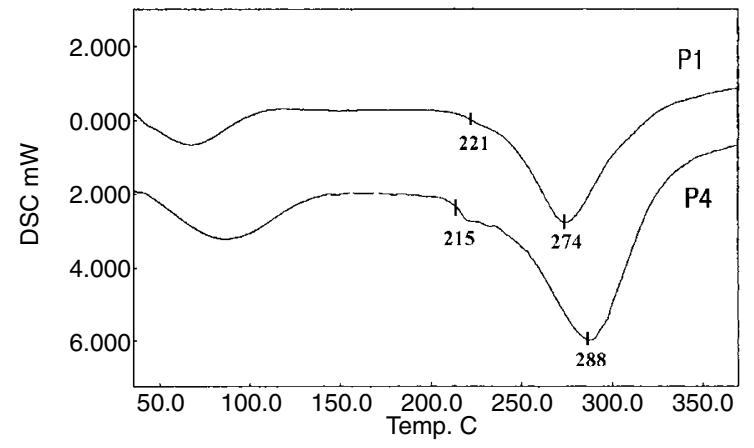

Figure 5. DSC thermogram of poly(o-hydroxyamide)s P1 and P4.
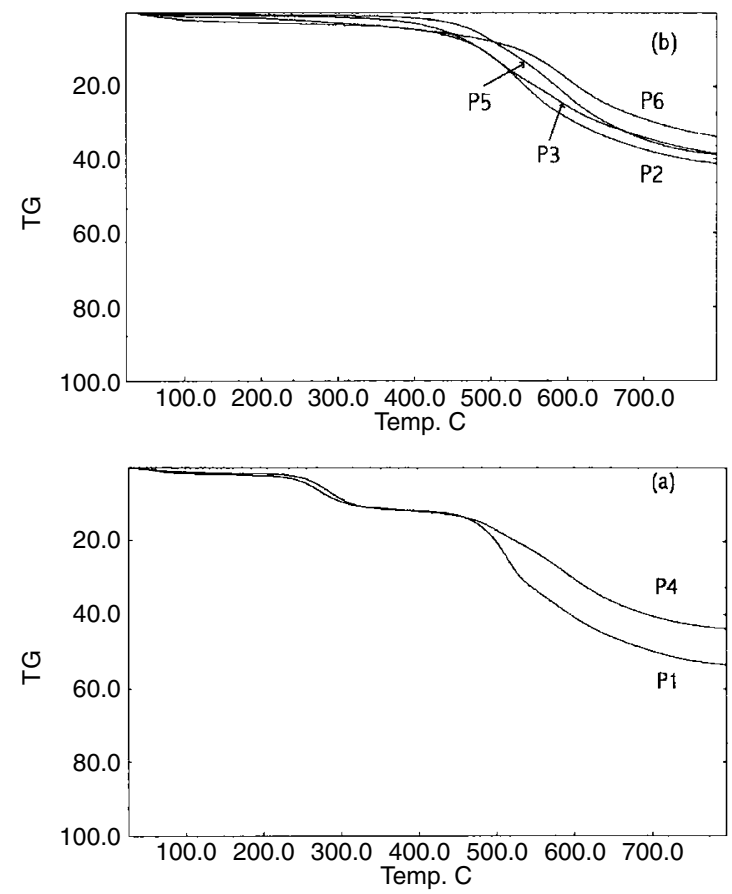

Figure 6. TGA thermogram of (a) HBPHAs and (b) HBPBOs.

and 6. Chemically cyclized polymer $\mathbf{P 6}$ was soluble in aprotic solvents such as NMP, DMAc, DMF, and DMSO when heating up to $100^{\circ} \mathrm{C}$ (Table I). This enhanced solubility of chemically cyclized HBPBO is a characteristic properties of hyperbranched polymers.
Table II. Solution and thermal properties of hyperbranched polymers

\begin{tabular}{ccccccc}
\hline Polymer & $\begin{array}{c}\eta_{\text {inh }}{ }^{\mathrm{a}} \\
\left(\mathrm{dL} \mathrm{g}^{-1}\right)\end{array}$ & $\begin{array}{c}M_{\mathrm{w}}{ }^{\mathrm{b}} \\
\left(\times 10^{4}\right)\end{array}$ & $M_{\mathrm{w}} / M_{\mathrm{n}}{ }^{\mathrm{b}}$ & $\begin{array}{c}T_{\mathrm{g}}{ }^{\mathrm{c}} \\
\left({ }^{\circ} \mathrm{C}\right)\end{array}$ & $\begin{array}{c}T_{5}{ }^{\mathrm{d}} \\
\left({ }^{\circ} \mathrm{C}\right)\end{array}$ & $\begin{array}{c}T_{10}{ }^{\mathrm{d}} \\
\left({ }^{\circ} \mathrm{C}\right)\end{array}$ \\
\hline P1 & 0.23 & $2.7^{\mathrm{e}}$ & $1.6^{\mathrm{e}}$ & 221 & 260 & 301 \\
P2 & - & - & - & $\mathrm{ND}^{\mathrm{g}}$ & 442 & 488 \\
P3 & 0.21 & $2.3^{\mathrm{e}}$ & $1.5^{\mathrm{e}}$ & $\mathrm{ND}$ & 425 & 489 \\
P4 & 0.17 & $13.1^{\mathrm{f}}$ & $1.7^{\mathrm{f}}$ & 215 & 274 & 318 \\
P5 & - & - & - & $217(225)^{\mathrm{h}}$ & 480 & 520 \\
P6 & 0.16 & $9.7^{\mathrm{f}}$ & $2.1^{\mathrm{f}}$ & $\mathrm{ND}$ & 424 & 537 \\
\hline
\end{tabular}

${ }^{\mathrm{a}}$ Measured at a concentration of $0.5 \mathrm{~g} \mathrm{dL}^{-1}$ in DMAc at $30{ }^{\circ} \mathrm{C}$. ${ }^{\mathrm{b}}$ Determined by GPC measurement in DMF containing lithium bromide $\left(0.01 \mathrm{~mol} \mathrm{~L}^{-1}\right)$ as an eluent with standard polystyrene calibration. ${ }^{c}$ Determined by DSC at a heating rate of $10^{\circ} \mathrm{C} \mathrm{min}^{-1}$ in nitrogen. ${ }^{\mathrm{d}}$ The temperature at which $5 \mathrm{wt} \%$ $\left(T_{5}\right)$ and $10 \mathrm{wt} \%$ of weight loss $\left(T_{10}\right)$ were determined by TGA at a heating rate of $10^{\circ} \mathrm{C} \mathrm{min}^{-1}$ in nitrogen. ${ }^{\text {ePerformed on }}$ JASCO HPLC 880 PU fitted Shodex KD $806 \mathrm{M}$ and 802.5

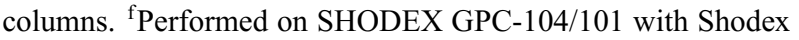
$\mathrm{KD} 806 \mathrm{M}$ and 802 columns. ${ }^{\mathrm{g}}$ Not detectable up to $380^{\circ} \mathrm{C}$ by DSC. ${ }^{\mathrm{h}}$ Glass transition temperature on second heating scan.

The solution properties of $\mathbf{P 6}$ were comparable to those of P4 (Table II). The $\eta_{\text {inh }}$ and $M_{\mathrm{w}}$ of $\mathbf{P 6}$ were 0.16 $\left(\mathrm{dL} \mathrm{g}^{-1}\right)$ and 97000 , which were slightly smaller than those of P4. These decrease of $\eta_{\text {inh }}$ and $M_{\mathrm{w}}$ for $\mathbf{P 6}$ compared to $\mathbf{P 4}$ might be caused by the elimination of water during the cyclodehydration. The chemical conversions of precursors to PBOs were confirmed by ${ }^{1} \mathrm{H}$ NMR and IR spectrophotometer as shown in Figures 2 and 7. In the ${ }^{1}$ HNMR spectra (Figure 2), P1 showed the characteristic amide peaks at $9.5 \mathrm{ppm}$ and tert-butyl peaks at $1.21 \mathrm{ppm}$, which came from the chemically modified end groups. The amide peaks of $\mathbf{P 1}$ disappeared clearly in P3. The amide peaks of $\mathbf{P 4}$ at $9.6 \mathrm{ppm}$ were also disappeared in P6. In the IR spectra shown in Figure 7, characteristic amide peaks of P1 and P4 observed at $1654 \mathrm{~cm}^{-1}$ disappeared completely in $\mathbf{P 3}$ and $\mathbf{P 6}$ and new characteristic peaks for benzoxazoles appeared at $1623 \mathrm{~cm}^{-1}$. These results supported the complete con- 

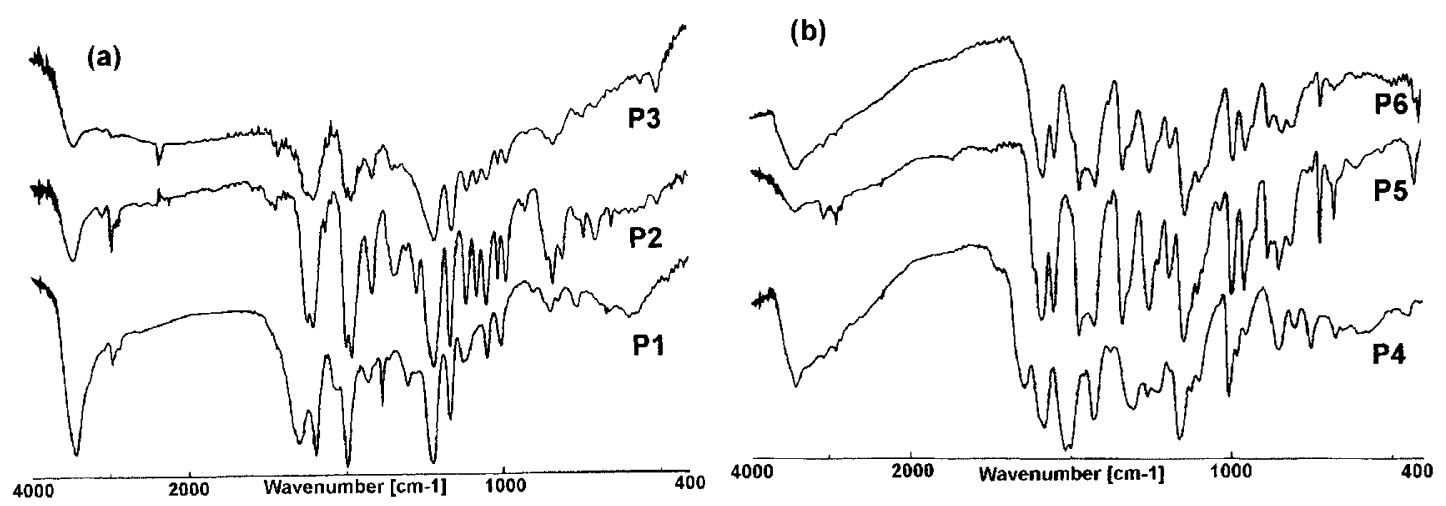

Figure 7. IR spectra of thermally (P2, P5) and chemically cyclized HBPBOs (P3, P6) and their precursors (P1, P4). Polymers prepared from (a) $\mathrm{AB}_{2}$ monomer and (b) $\mathrm{A}_{2} \mathrm{~B}$ monomer.

version of HBPHAs to HBPBOs was achieved by the chemical cyclization.

\section{Thermal Properties of Polymers}

Polymer P4 showed two step weight loss in the TGA thermogram (thermogram (a) in Figure 6). It is clear that the first step weight loss $(7.2 \mathrm{wt} \%)$ at $255-318^{\circ} \mathrm{C}$ is due to the elimination of water during the cyclodehydration of HBPHA precursor to form the HBPBO. It is well corresponding to the calculated weight loss (7.5 wt\%). Thermally or chemically cyclized polymers, P5 or P6, showed only one step weight loss having the $10 \mathrm{wt} \%$ weight loss $\left(T_{10}\right)$ at $520^{\circ} \mathrm{C}$ and $537^{\circ} \mathrm{C}$ in nitrogen (Table II) which was a little bit higher than those of $\mathbf{P 2}$ and $\mathbf{P 3}\left(488^{\circ} \mathrm{C}, 489^{\circ} \mathrm{C}\right)$. This gap seemed to be caused by the difference of molecular weight between the two polymers. TGA results indicated that these polymers were thermally stable which was not inferior compared to their linear analogues..$^{29,30}$ Thermally cyclized polymers, $\mathbf{P 2}$ and $\mathbf{P 5}$, showed similar TGA patterns to chemically cyclized ones (P3 and P6). Glass transition temperatures $\left(T_{\mathrm{g}}\right)$ of $\mathbf{P 1}, \mathbf{P 4}$, and $\mathbf{P 5}$ were $221{ }^{\circ} \mathrm{C}, 215^{\circ} \mathrm{C}$, and $217^{\circ} \mathrm{C}$ respectively, but the $T_{\mathrm{g}}$ values of the other polymers were not detected up to $380^{\circ} \mathrm{C}$ by DSC.

\section{CONCLUSION}

We prepared the two types of new monomers for hyperbranched polybenzoxazoles. The hyperbranched poly(o-hydroxyamide)s as precursors of polybenzoxazole were synthesized successfully by self-polycondensation of $\mathrm{AB}_{2}$ and $\mathrm{A}_{2} \mathrm{~B}$ type monomers in the presence of DBOP as a condensing agent. HBPHA precursors have excellent solubility in aprotic solvents having the moderate molecular weight. Although in this study, the molecular weights were determined by GPC with polystyrene calibration, we are trying the alternative measurement of the abso- lute molecular weights using the GPC with a laser light scattering detector. The conversion of $\operatorname{poly}(o-$ hydroxyamide) to polybenzoxazole was carried out by thermal or chemical cyclodehydration. The polymers, which were chemically cyclodehydrated in polyphosphoric acid (PPA) have also good solubility in aprotic solvents as well as excellent thermal stability having the $T_{10}$ at $489-537^{\circ} \mathrm{C}$, whereas thermally cyclodehydrated polymers were insoluble in the same solvents.

Acknowledgment. We thank Prof. Mitsuru Ueda of Tokyo Institute of Technology for his helpful discussion.

\section{REFERENCES}

1. K. C. Brinker, D. D. Cameron, and I. M. Robinson, U.S. Patent 2904537 (Sep. 15, 1959).

2. Y. Imai, I. Taoka, K. Uno, and Y. Iwakura, Makromol. Chem., 83, 167 (1965).

3. C. Jr. Arnold, J. Polym. Sci., Macromol. Rev., 14, 265 (1979).

4. P. E. Cassidy, "Thermal stable polymers", Mercel Dekker, New York, N.Y., 1980, p 154.

5. J. F. Wolfe and F. E. Arnold, Macromolecules, 14, 909 (1981).

6. J. F. Wolfe, Encycl. Polym. Sci. Tech., 11, 601 (1988).

7. A. Kraft, A. C. Grimsdale, and A. B. Holmes, Angew. Chem. Int. Ed., 37, 402 (1998).

8. Y. Maruyama, Y. Oishi, M. Kakimoto, and Y. Imai, Macromolecules, 21, 2305 (1988).

9. P. E. Cassidy, T. M. Aminabhavi, and J. M. Farley, J. Macromol. Sci., Rev. Macromol. Chem. Phys., c29, 365 (1989).

10. W. J. Joseph, J. C. Abed, R. Mercier, and J. E. Mcgrath, Polymer, 35, 5046 (1994).

11. K. H. Park, M. Kakimoto, and Y. Imai, J. Polym. Sci., Part A: Polym. Chem., 36, 1987 (1998).

12. D. A. Tomalia, A. M. Naylor, and W. A. Goddard III, Angew. Chem. Int. Ed., 29, 138 (1990).

13. J. M. J. Fréchet, C. J. Hawker, I. Gitsov, and J. W. Leon, J. Macromol. Sci., Pure Appl. Chem., A33, 1399 (1996).

14. B. I. Voit and D. Wolf, Tetrahedron, 53, 15535 (1997).

15. H. R. Kricheldorf, O. Bolender, and T. Wollheim, Macromolecules, 32, 3878 (1999). 
16. M. Jikei and M. Kakimoto, Prog. Polym. Sci., 26, 1233 (2001).

17. S. Srinivasan, R. Twieg, J. L. Hedrick, and C. J. Hawker, Macromolecules, 29, 8543 (1996).

18. Y. H. Kim, J. Polym. Sci., Part A: Polym. Chem., 36, 1685 (1998).

19. G. Yang, M. Jikei, and M. Kakimoto, Macromolecules, 32, 2215 (1999).

20. D. S. Thompson, L. J. Markoski, J. S. Moore, I. Sendijarevic, A. Lee, and A. J. McHugh, Macromolecules, 33, 6412 (2000).

21. B. Voit, J. Polym. Sci., Part A: Polym. Chem., 38, 2505 (2000).

22. Z. H. Gong, M. Leu, F. I. Wu, and C. F. Shu, Macromolecules, 33, 8527 (2000).

23. J. B. Baek, S. R. Simko, and L. S. Tan, Polym. Prepr., (Am. Chem. Soc., Div. Polym. Chem.), 42(2), 502 (2001).
24. H. Ahne, R. Rubner, and E. Kuehn, Euro. Patent 23662 A1 (Feb. 11, 1981).

25. T. K. Kim, K. Y. Choi, K. S. Lee, D. W. Park, and M. Y. Jin, Polym. Bull., 44, 55 (2000).

26. C. S. Hong, M. Jikei, and M. Kakimoto, J. Photopolym. Sci. Technol., 15, 219 (2002).

27. M. Ueda, T. Morosumi, M. Kakuta, and R. Sato, Polym. J., 22, 733 (1990).

28. T. Hayakawa, T. Morishita, M. Okazaki, M. Ueda, K. Takeuchi, and M. Asai, J. Polym. Sci., Part A: Polym. Chem., 38, 3875 (2000).

29. M. Ueda, H. Sugita, and M. Sato, J. Polym. Sci., Part A: Polym. Chem., 24, 1019 (1986).

30. B. A. Reinhardt, Polym. Commum., 31, 453 (1990). 